\title{
Avaliação do impacto da utilização de crédito, da educação e da escolha do canal de comercialização na horticultura: caso do núcleo rural do Distrito Federal
}

\author{
Sebastião Eustáquio Pereira ${ }^{1}$ \\ Adelaide dos Santos Figueiredo ${ }^{2}$ \\ Paulo R. A. Loureiro ${ }^{3}$
}

Resumo: O objetivo deste artigo consiste identificar a influência de diversos fatores relacionados com a renda do agricultor familiar, que podem reforçar ou não a idéia básica contida na política de fortalecimento da agricultura familiar implementada pelo Governo desde 1996. Os retornos foram estimados baseados em regressão linear (OLS) em dois estágios, com a equação do segundo momento sendo corrigida pela incorporação da razão inversa de Mills gerada com o resultado do modelo probit, onde é estimada a possibilidade do horticultor demandar ou não crédito. Ficou evidenciada a desvantagem da negociação através dos grandes supermercados, que tendem a comprimir, conforme constatado por Melo (2001), a remuneração dos fornecedores de hortaliças.

Palavras-chave: Agricultura familiar, horticultura, crédito e comercialização.

Classificação JEL: C33, Q12,Q13, Q18

\footnotetext{
${ }^{1}$ Mestre em Economia e professor do Curso de Ciências Contábeis da Universidade Católica de Brasília. eustaquio@ucb.br

2 Doutora em Engenharia de Transportes, pesquisadora e professora do Mestrado e Doutorado em Economia de Empresas da Universidade Católica de Brasília. adelaid@pos.ucb.br

${ }^{3}$ Doutor em Economia, professor e pesquisador do Mestrado e Doutorado em Economia de Empresas da Universidade Católica de Brasília. loureiro@pos.ucb.br
} 
Abstract: This paper aims to identify the influence of several factors linked with the familiar farmer income, which can reinforce or not the basic idea of policy of incentive of the familiar agricultural implemented by Government since 1996. The profits were estimated based on OLS linear regression in two stages, with the equation of second moment has been adjusted by incorporation of inverse ration of Mills generate with the result of probit model, where is estimated the possibility of the producers of vegetables demand or not the credit. It was evident the disadvantage of trade via the big supermarkets, because they contribute to reduce, in according to Mello (2001), the gains of vegetables producers.

Key words: familiar agricultural, credit, horticulture and commercialization.

Classificação JEL: C33, Q12,Q13, Q18

\section{Introdução}

A cidade de Brasília experimentou notável crescimento demográfico no período de 1990 a 2000. Esse crescimento do mercado interno estimulou a produção de bens de consumo. A orientação da produção, antes voltada para subsistência, passa a ter o estímulo de expansão do mercado consumidor com o crescimento demográfico da cidade. $\mathrm{O}$ aumento vertiginoso do mercado interno, e o apoio técnico do Governo viabilizaram a utilização intensiva da terra em áreas próximas à cidade e propiciou o estabelecimento de empreendimentos agrícolas e agro-industriais, especialmente os de estrutura familiar, gerando impacto direto sobre o emprego e a renda do Distrito Federal.

Segundo a Secretaria de Agricultura, Pecuária e Abastecimento (SEAPA, 2004), cada hectare plantado gera em média quatro empregos diretos e um número expressivo de empregos indiretos na comercialização. A horticultura representa um segmento do agronegócio de alto valor social, pois são cultivos de uso intensivo em mão-de-obra. $\mathrm{O}$ principal desafio enfrentado por esse agronegócio que apresenta taxas de crescimentos de cerca de $4,5 \%$ ao ano é colocar-se no mercado de forma lucrativa. 
A escolha dessa comunidade como base de pesquisa foi feita com o propósito de testar as hipóteses de que o crédito, a educação e a escolha do canal de distribuição possuem relevância na constituição da renda da agricultura familiar, pois se trata de segmento de destaque no cenário nacional por sua produtividade e uso intensivo de tecnologia e que ainda assim apresenta indícios de descapitalização, reflexo da baixa remuneração de seus produtos, endividamento e baixo poder de negociação na comercialização de seus produtos (Melo, 2001).

Dado esse quadro, a agricultura familiar no Distrito Federal, experimentou um período de significativo crescimento, taxa média de crescimento da produção de 6,9\% no período de 1990 a 1999. Para se ter uma idéia, segundo esse mesmo autor, em 1991, existiam 5.962 imóveis rurais e, em 1997, esse número alcançou 14.146 imóveis dos quais cerca de $61 \%$ com áreas de menos de 10 ha. Em 2000, os produtores de hortaliças do Distrito Federal ocupavam uma área de 7.458 ha, distribuídos em 15 núcleos rurais. A área de cultivo apresentou crescimento médio de 5,1\% na década de 1990 (Melo, 2001).

Dentre as suas principais vantagens competitivas podemos destacar: disponibilidade de terra e água de boa qualidade, mão-de-obra familiar abundante, infra-estrutura de assistência técnica governamental e proximidade do mercado consumidor. Neste contexto, a realidade sobre a qual assenta-se a agricultura familiar em Brasília é favorável para uma produção eficiente, eficaz e competitiva e capaz de gerar riqueza para seus participantes, contribuindo para o crescimento econômico da Região.

Neste contexto, esse trabalho tem como objetivo avaliar se (1) efetivamente o crédito tem contribuído para o crescimento econômico regional, especialmente, no Distrito Federal. (2) Também será testada a importância da educação e do canal de comercialização na formação da renda desses produtores.

Feder et al. (1990) mostra que o crédito é necessário para viabilizar a produção uma vez que o agricultor possui um ciclo de renda sazonal e precisa de antecipação de recursos para compra de insumos e equipamentos necessários para produzir. A concentração da produção em uma mesma época é um fator crítico que, em geral, dificulta e compromete o preço de venda dos produtos agrícolas, tornando incerta a renda do agricultor e justificando a preocupação do governo em também criar 
mecanismos que dêem maior poder de mercado ao segmento, no momento da comercialização.

Para responder a essas questões, foram analisadas as diversas abordagens, como os modelos sugeridos por Feder et al. (1990), Khandker e Faruqee (2001), Carter (1988), Carter \& Weibe (1990) e Sial \& Carter (1996), para escolha das variáveis que relacionam crédito com renda na agricultura familiar.

O objetivo deste artigo consiste em identificar a influência de diversos fatores relacionados com a renda do agricultor familiar, que podem reforçar ou não a idéia básica contida na política de fortalecimento da agricultura familiar implementada pelo Governo desde 1996.

A seção seguinte desse artigo apresenta a fundamentação teórica da influência do crédito na agricultura, incluindo resultados observados em outros países e no Brasil. A seção três, mostra a especificação empírica do modelo. A seção Quarta descreve os dados e as características da amostra de horticultores do Distrito Federal. Na quinta seção são apresentados os resultados, e na sexta parte, as conclusões.

\section{Revisão de literatura}

Esse estudo alinha-se ao raciocínio de Schultz (1964) de que os agricultores familiares dos países subdesenvolvidos são eficientes, maximizadores de lucro, alocam seus recursos de forma racional, mas seu sistema produtivo possui baixa tecnologia e poucas oportunidades econômicas, o que dificulta o aumento de sua renda, ou seja, de seu crescimento econômico.

Conforme Abramovay (1992), a raiz dessa questão está numa dupla inseparável: eficiência e maximização de lucro, Schultz (1964), portanto, refuta a noção de que a produtividade marginal do trabalho na agricultura dos países pobres seja zero, ou, em outras palavras que existe uma parte da população ativa cujo trabalho em nada contribui para o produto.

A relação entre educação e agricultura foi enfatizada nos estudos de Schultz (1964). Em seus trabalhos empíricos esse autor enfatizou que a educação desses trabalhadores seria um elemento crucial para melhorar a capacidade de uso eficiente dos recursos disponíveis e, portanto, de 
aumentar a renda desses trabalhadores. Ressaltou ainda que vários economistas da época foram ingênuos na avaliação do efeito econômico da educação dos agricultores. Embora concorde que o valor da escolaridade na agricultura depende das oportunidades disponíveis para os agricultores modernizarem seus processos produtivos. Silva e Kassouf (2000), inter alia, investigaram a existência de retornos diferenciados à educação e treinamento. Loureiro, Carneiro e Sachsida (2004) identificaram no que diz respeito aos rendimentos nos dois anos considerados (1992 e 1998), o retorno à escolaridade para os homens foi de 18,53 \% e 13,09\%, no setor urbano, enquanto a taxa de retorno à escolaridade das mulheres foi de $20,92 \%$ e $11,63 \%$, respectivamente. A relevância econômica da variável educação nos modelos estimados para os setores urbano e rural, está relacionada ao fato de que essa variável consegue captar a influência do capital humano dos trabalhadores urbanos e rurais.

A agricultura familiar pode ser definida a partir de três características centrais: a) a gestão da unidade produtiva e dos investimentos nela realizados são feita por indivíduos que mantêm entre si laços de sangue ou de casamento; b) a maior parte do trabalho é igualmente fornecida pelos membros da família; c) a propriedade dos meios de produção (embora nem sempre da terra) pertence à família e é em seu interior que se realiza sua transmissão em caso de falecimento ou de aposentadoria dos responsáveis pela unidade produtiva. (Guanziroli 1997).

O crédito é um instrumento importante para a agricultura por possibilitar o investimento em capital fixo e capital humano, insumos básicos da atividade, facilitando o processo de produção e de inovação. O crédito também permite que o agricultor possa regular o fluxo de seu consumo pessoal e de insumos para produção, compatibilizando-o com o fluxo de sua renda, que pode ser contínuo ou sazonal.

Antes de prescindir do crédito, no entanto, a agropecuária brasileira passou por uma verdadeira revolução gerencial e tecnológica para responder aos novos desafios gerados pelo processo de globalização da economia brasileira. O setor teve que superar a dependência do governo com relação à necessidade de financiamentos e políticas de preços mínimos, por conta do processo de competição a que foi submetido com as alterações econômicas ocorridas.

Essa evolução fez surgir o mercado do agronegócio que detém cerca de 
$29 \%$ do PIB brasileiro. Ainda segundo essa instituição, “agronegócio é um conjunto das atividades derivadas e dependentes da produção agropecuária. Difere do modelo clássico de setores econômicos (primário, secundário e terciário), pois trata a cadeia produtiva como um conjunto de agentes que começa nas indústrias de insumos, passa pela produção rural, chega às indústrias de beneficiamento e industrialização dos produtos e termina nas diversas redes de distribuição de atacado e varejo do país".

O processo de globalização e a redução do apoio do governo trouxeram para o setor rural o desafio de modernizar e profissionalizar seus processos produtivos para satisfazer os requisitos de qualidade, escalas e eficiência exigíveis para sobrevivência. Na década de 1990, esse esforço foi favorecido pela estabilização econômica, os avanços em termos de pesquisa e desenvolvimento que permitiram a redução de riscos associados aos aspectos biológicos e climáticos, graças aos avanços obtidos por empresas privadas e públicas, com destaque para a Empresa Brasileira de Pesquisa Agropecuária. O crédito continua sendo necessário e várias alternativas foram criadas para viabilizar o custeio e o investimento na agropecuária. A agricultura familiar passou, a partir de 1996, a contar com uma política de acesso ao crédito com uma série de medidas, e que foram além da simples disponibilização de recursos específicos, mas outras medidas que favoreciam esse acesso. Feder et al. (1990) concluíram que, para as famílias com restrição de crédito, $1 \%$ de aumento na liquidez (crédito) desses trabalhadores representava um aumento de $0,04 \%$ na sua produção.

As instituições financeiras formais e informações possuem papel fundamental na distribuição do crédito, mas sua eficiência depende de uma série de fatores que vão desde a diminuição dos custos operacionais até reduzida assimetria de informações. O problema da assimetria de informações surge quando certos padrões de comportamentos não são observáveis por todas as partes envolvidas na transação, sem que haja um custo informacional. Essa possibilidade permite a ocorrência de comportamentos oportunísticos por parte dos agentes que possuem informações não compartilhadas com os demais agentes do mercado. A questão da assimetria das informações é que nem sempre as informações necessárias para a condição ótima de realização de uma transação estão, de forma homogênea, disponíveis aos agentes envolvidos, o que 
acaba levando a resultados não ótimos de negociação em relação aos modelos neoclássicos de equilíbrio.

Para Carter (1988) e Carter e Weibe (1990) a avaliação da efetividade dessas políticas não é trivial, envolve dois aspectos muito importantes - custos e benefícios - e, especialmente, mensurar os benefícios é freqüentemente problemático porque os recursos são fungíveis ${ }^{4}$ e porque não é claro se a parcela de crédito tomada reflete a restrição de crédito ou características não observadas do tomador.

Um dos problemas enfrentados por Sial \& Carter (1996) foi que os dados disponíveis para o estudo não continham a informação sobre crédito e, portanto, não seria possível separar os agricultores que recebiam dos que não recebiam crédito na região. Para resolver esse problema partiram do modelo utilizado por Carter (1989) para análise de programa de crédito, hipótese básica do trabalho de Sial \& Carter (1996) é de que o mercado de crédito é ineficiente, por causa da presença de assimetria e informação e ocorrência de seleção adversa. Caso essa hipótese fosse rejeitada, então o impacto esperado do programa de empréstimos é insignificante na função de renda (output supply).

Na concepção de Gasques et al. (2000), a principal alteração no conceito de financiamento agrícola diz respeito às fontes de recursos e aos subsídios. No paradigma antigo, os financiamentos eram obtidos via governo ou doações, enquanto os subsídios eram elevados em função de baixas taxas de juros fixadas para os empréstimos. Considerando-se o novo paradigma, os financiamentos serão resultados de depósitos voluntários, e os subsídios serão baixos ou inexistentes.

Spolador (2001) indica que o mercado de crédito para a agricultura apresenta características que impedem o equilíbrio de mercado perfeito e que, portanto, acabam por alterar seu funcionamento tais como: risco climático, custos de transações, volatilidade dos preços dos produtos agrícolas e assimetria de informações.

Para Khandker \& Faruqee (2001), ambos, crédito formal e informal, são importantes na agricultura. Tendo em vista que os planos de financiamentos agrícolas são subsidiados, os formuladores de políticas devem conhecer se tais planos são merecedores dessa ajuda, quem recebe subsídio e se efetivamente esse plano ajuda os seus beneficiários. O crédito é considerado importante porque capitaliza os agricultores e empreendedores a realizarem

${ }^{4}$ Substituíveis por outros da mesma espécie, qualidade e quantidade. 
novos investimentos ou adotarem novas tecnologias. Isto facilita o consumo através da viabilização de capital de giro e reduz a necessidade de recursos pessoais do processo. Usando dados de pesquisa com famílias rurais do Paquistão, estimaram a efetividade do Agricultural Development Bank of Pakistan (ADBP) como sistema de distribuição de crédito. Os resultados mostraram que o ADBP contribui para a prosperidade das famílias e que o impacto é maior para os pequenos proprietários, mas os grandes proprietários, no entanto, foram os que receberam a maior parte dos recursos.

Gasques \& Spolador (2003) avaliaram os efeitos da taxa de juros e das políticas de apoio interno de apoio à agricultura. O seu estudo mostrou efeito positivo da estabilidade econômica, principalmente por conta da redução da taxa de juros e a maior disponibilização de recursos. A média de recursos aplicados por ano, no período de 1990 a 1997, foi de R 8 bilhões, no período de 1996 a 2001, atingiu R $\$ 15$ bilhões. "Mas apesar desse aumento da quantidade de recursos para agricultura por meio do Sistema Nacional de Crédito Rural, o financiamento continua de acesso restrito e sendo um forte fator limitativo do desenvolvimento da agricultura no que se refere ao aumento da produção e às possibilidades de investimentos".

Gasques \& Bastos (2003) mostram que o crédito de investimento contribui para o aumento do produto e da produtividade da agricultura. Os autores ressaltaram que a retomada da importância do crédito de investimento é um fato recente da política de crédito rural do país. Observaram, ainda, o aumento do percentual de agricultores com segundo e terceiro graus completos. Os agricultores valorizam a assistência técnica e tratam seus empreendimentos como empresas. Os autores concluem, entretanto, que a assimetria de informações e seleção adversa são características sempre presentes no mercado de crédito, dando origem ao racionamento de crédito (apud Stiglitz \& Weiss) como um procedimento de otimização. Além disso, a intervenção do governo na fixação de taxa de juros e concessão de subsídios para o setor agrícola é comum em muitos países, requerendo racionamento.

No contexto macroeconômico, o crescimento de determinado setor é avaliado em termos de sua participação no PIB do País. Observandose os dados de crescimento ao longo de um período de tempo em que são relacionados o crescimento da agricultura com o crescimento do PIB, notam-se alguns pontos importantes. No caso da agricultura familiar será adotada a renda como referencial de crescimento econômico. 
A relação entre o crescimento do PIB agrícola e o crédito rural no Brasil foi estudada por Conceição et al. (1998), utilizando o teste de causalidade de Granger para o período de 1971 a 1995. O resultado desse estudo constatou a existência de causalidade, no sentido de Granger, entre as variáveis crédito agrícola e o PIB. O estudo sugere não ser prudente negligenciar o papel do crédito na alavancagem do setor agrícola.

Com relação ao mercado de crédito até 1993 não existiam recursos para o financiamento da agricultura familiar. $\mathrm{O}$ agricultor familiar era considerado "mini-produtor" e disputava com os grandes produtores, sem nenhuma diferenciação, os escassos recursos destinados ao crédito rural. O Programa Nacional de Fortalecimento da Agricultura Familiar do Governo Federal (PRONAF), foi criado em 1996, como uma linha de crédito especial destinada a esse segmento. Embora seja insuficiente pensar em promover desenvolvimento rural apenas com política de crédito, criou-se uma expectativa em torno da efetiva promoção do desenvolvimento através do PRONAF.

Em 2002 foi elaborado estudo, no âmbito do Ministério do Desenvolvimento Agrário, pela Fundação de Economia de Campinas (FECAMP), com o objetivo geral de avaliar a existência de possíveis associações entre a presença do PRONAF e variáveis econômicas, tais como renda, produtividade e tecnologia (FECAMP 2002). O trabalho apoiou-se em pesquisa de campo realizada em diversos estados, foram utilizadas 27 variáveis, qualitativas e quantitativas, e a amostra contemplou 1.994 domicílios de produtores rurais divididos em dois grupos: os que receberam crédito do PRONAF (996 domicílios) e os que não o receberam (998 domicílios).

O relatório final desse trabalho aponta que o PRONAF mostrou efeito negativo e significativo, de $20 \%$ a menos, na renda per capita, principal foco do estudo, apontando que esse efeito pode ser decorrente do fato de serem os agricultores mais pobres os que recorrem aos financiamentos do programa. O estudo não é conclusivo pelo fato da análise ser de apenas um ano, e sugere o acompanhamento da amostra estudada, sob a forma de painel, para proporcionar conclusões mais robustas sobre os impactos do programa.

Os efeitos do Programa Nacional de Fortalecimento da Agricultura Familiar (PRONAF) foram analisados de forma preliminar por Feijó (2003) utilizando-se do índice Tornqvist-Theil de multifator para avaliar os efeitos de mudanças na produtividade dos pequenos agricultores que pudesse ser atribuída ao acesso a linhas de crédito. A sua principal conclusão foi de 
ausência de impacto produtivo significativo do programa, a produtividade das culturas beneficiadas não foi muito diferente das não beneficiadas.

\section{O modelo}

No modelo de consumo, produção e investimento para agricultura familiar de Feder et al. (1990) é assumida que as dotações iniciais de recursos dos produtores podem ser aumentadas a obtenção de crédito e pressupõe que as famílias alocam os recursos colados à sua disposição no início do período para os seguintes usos: (a) consumo, (b) investimento, (c) compra de insumos para produção (incluindo mão de obra e fertilizantes). A otimização ocorre em dois cenários (i) a oferta de crédito é maior ou igual à demanda e (ii) a oferta de crédito é menor que a hipotética demanda (isto é crédito racionado).

Os retornos foram estimados baseados em regressão linear (OLS) em dois estágios, com a equação do segundo momento sendo corrigida pela incorporação da razão inversa de Mills gerada com o resultado do modelo probit, onde é estimada a possibilidade do horticultor demandar ou não crédito. As variáveis que incorporam essa tomada de decisão, geralmente, não são diretamente observáveis, para cada indivíduo i. Pode-se, então, definir $y^{*}$ como uma preferência (não-observável) latente, tal como:

$$
y_{i}^{*}=\beta_{i} X_{i k}+\mu_{i}
$$

Onde $\mathrm{x}_{\mathrm{i}}$ representa um conjunto de variáveis explicativas relacionadas ao produtor i. A decisão de produzir pode ser descrita em termos de uma variável dummy, $\mathrm{y}$, de forma que $\mathrm{y}_{\mathrm{i}}=1$ se o produtor decidiu produzir, e $\mathrm{y}_{\mathrm{i}}=0$ se não decidiu produzir. $\mathrm{O}$ parâmetro $\beta_{\mathrm{i}}$ mede o efeito de uma mudança em $\mathrm{X}_{\mathrm{ik}}$ sobre a variável latente (não-observável) $\mathrm{y}_{\mathrm{i}}{ }^{*}$. A importância desses efeitos em termos de interpretação é que a variável latente e os efeitos marginais têm somente significado ordinal e não cardinal. O sinal de $\beta_{\mathrm{k}}$ determina a direção do efeito, e o efeito tende a ser maior quanto maior for $\beta_{\mathrm{k}}$. Quanto maior o valor de $\mathrm{y}_{\mathrm{i}}{ }^{*}$, maior a probabilidade de o indivíduo aceitar trabalhar. 
A equação de rendimento é a seguinte:

$$
W_{i}=\delta Z_{i}+\varepsilon_{1 i}
$$

onde $\mathrm{W}$ é o logaritmo do salário, $\mathrm{Z}$ é um vetor de características dos produtores, $\delta$ é um conjunto de parâmetros e $\mu$ é vetor de termo erros aleatórios e que assume as propriedades estatísticas usuais. Deve-se observar, no entanto, que dado que a amostra sobre a participação do trabalhador no mercado de trabalho não é aleatória, pode ocorrer viés de seletividade amostral. De acordo com Heckman (1974), se a equação (2) de rendimentos for estimada utilizando o método dos mínimos quadrados ordinários (MQO), os parâmetros $\delta$ seriam viesados. No entanto, se a equação de rendimentos usasse uma função lambda $\lambda$ (.), dada por $\lambda()=.\frac{\phi\left(\beta X_{i} / \sigma_{\mu}\right)}{\Phi\left(\beta X_{i} / \sigma_{\mu}\right)}$, como variável explicativa adicional, conhecida como o inverso da razão de Mill, produziria estimadores consistentes de $\delta$.

Assim, o procedimento de Heckman $(1974,1990)$ deve ser utilizado para a obtenção de estimadores consistentes dos parâmetros nas equações de rendimentos estimados por mínimos quadrados ordinários, da seguinte forma:

$$
W_{i}=\delta Z_{i}+\frac{\phi\left(\beta X_{i} / \sigma_{\mu}\right)}{\Phi\left(\beta X_{i} / \sigma_{\mu}\right)} \Theta
$$

ou

$$
W_{i}=\delta Z_{i}+\lambda_{i} \Theta
$$

O procedimento descrito acima permite que se obtenham estimativas consistentes sobre o rendimento dos produtores rurais, controlando-se por características individuais.

A aplicação desse modelo por Feder et al. (1990) nos dados da agricultura chinesa mostrou que, para as famílias com restrição de crédito, $1 \%$ de aumento na liquidez (crédito) desses trabalhadores representava um aumento de $0,04 \%$ na sua produção. O estudo baseou-se em dados coletados em Gongzhuling, localizado na província Jilin, região 
produtora de grãos no nordeste da China, onde as condições climáticas determinam uma única produção anual. A amostra original consiste em 200 households selecionados de forma aleatória de oito comunidades também escolhidas de forma aleatória.

A idéia do presente trabalho é utilizar esse modelo para estudar o comportamento da renda dos horticultores do Distrito Federal. Assim foi aplicado o questionário aos produtores vinculados aos diversos núcleos rurais. As informações coletadas abrangem características familiares, da produção, de comercialização e do crédito dos produtores. Os dados sobre os fatores determinantes da oferta e demanda de crédito da agricultura familiar, o vetor Z (que envolve tais variáveis) foi substituído para uma variável dummy, que assume valor 1 se o produtor possui alguma restrição de crédito e zero para os produtores com auto-suficiência de recursos para produção.

\section{Os dados}

Os agricultores que já utilizaram financiamento de custeio e investimento, de qualquer natureza, e o nonborrowers que responderam que não conseguiram obter financiamento ou não possuem as garantias exigidas como condição de acesso ao crédito, foram classificados como agricultores com restrição de crédito. Conforme mostrado na Tabela 2, cerca de $79 \%$ dos horticultores do Distrito Federal trabalham com crédito racionado. Existe uma parcela dos produtores que possuem liquidez própria suficiente para bancar seus empreendimentos. Os financiamentos são mais utilizados (43\%) para o custeio da produção e somente $23 \%$ utilizam tais fontes de recursos para realização de investimento. Uma relativa surpresa foi que apenas $47 \%$ dos financiamentos de custeio e investimento foram declarados como originários de bancos.

Tabela 1 - Distribuição do crédito por finalidade e alcance forma da restrição de crédito

\begin{tabular}{rrrrr}
\hline Dummy & fcusteioD & finvestD & cred_constrD & dbancosD \\
\hline $\mathbf{0}$ & 166 & 224 & 62 & 153 \\
1 & 125 & 67 & 229 & 138 \\
$\mathrm{~N}^{\circ}$ obs & 291 & 291 & 291 & 291 \\
\hline \% participação (1) & $43.0 \%$ & $23.0 \%$ & $78.7 \%$ & $47.4 \%$ \\
\hline \hline
\end{tabular}

Fonte: Questionário horticultura 2003, Stata - Statistics/Data Analysis 7.0. 
A estimação da importância da escolaridade, canal de venda e de credito agrícola é feita utilizando-se dados de pesquisa realizada pela Universidade Católica de Brasília, em parceria com a EMATER-DF, junto aos horticultores dos diversos núcleos rurais assistidos, em novembro de 2003. Os dados dos diversos núcleos rurais foram coletados por intermédio da aplicação do questionário descrito no Anexo 1. A amostra de 291 produtores dessas localidades foi escolhida aleatoriamente. O questionário elaborado investiga as características socioeconômicas dos horticultores, com as perguntas agrupadas em 4 (quatro) blocos que tratam: (1) do perfil do produtor; (2) perfil da atividade; (3) infra-estrutura disponível; e (4) avaliação e capacidade de formação de grupos de comercialização.

Os dados utilizados no trabalho caracterizam-se como uma agregação de microdados na forma de cross section de 291 horticultores entrevistados entre outubro e novembro de 2003. A amostra caracteriza-se empreendimentos agrícolas com menos de dois empregados permanentes e área média em torno de 2 ha, sendo a área cultivada em média de 8 ha. $O$ nível de escolaridade ficou acima da média nacional com cerca de 8 anos de estudo, sendo que $50 \%$ dos horticultores possuem apenas 4 anos de escolaridade.

Tabela 2 - Características gerais da amostra

\begin{tabular}{lrrrr}
\hline Variable & Mean & Std. Dev & Min & Max \\
\hline renda - em salários mínimos & 2,41 & 1,10 & 1,00 & 4,00 \\
educ & 8,17 & 5,42 & 4,00 & 24,00 \\
nfam & 1,53 & 0,72 & 1,00 & 4,00 \\
nempreg & 1,46 & 1,01 & 0,00 & 7,00 \\
area & 21,20 & 38,46 & 0,00 & 474,00 \\
area_cult & 7,66 & 9,40 & 0,00 & 130,00 \\
\hline \hline
\end{tabular}

Fonte: Questionário horticultura 2003, Stata - Statistics/Data Analysis 7.0.

A renda média gira em torno de 2,4 salários mínimos mensais. Outros aspectos interessantes é que $95 \%$ dos entrevistados moram na área rural, $72 \%$ são casados e $74 \%$ participam mesmo que eventualmente de atividades educativas vinculadas à sua atividade, como palestras, cursos técnicos, dia de campo e visitas e experiências práticas. 
Avaliação do Impacto da utilização de Crédito, da educação e da escolha do canal de comercialização na Horticultura: Caso do Núcleo Rural do Distrito Federal

Tabela 3 - Estatística descritiva da amostra - perfil da atividade

\begin{tabular}{lrrr}
\hline Variável & Característica & \multicolumn{2}{c}{ Freq. Percent } \\
\hline Pessoas que trabalham na produção & de 1 a 2 & 268 & 92,1 \\
Pessoas que recebem salário & de 1 a 2 & 268 & 92,1 \\
Renda em salários mínimos & de 1 a 4 & 173 & 59,5 \\
Utilizam assistência técnica & pública & 216 & 83,5 \\
& privada & 50 & 17,2 \\
Já utilizou financiamento & custeio & 125 & 43,0 \\
& investimento & 67 & 23,0 \\
Origem do financiamento & bancos & 138 & 47,4 \\
Produtor com crédito & racionado & 229 & 78,7 \\
\hline \hline
\end{tabular}

Fonte: Questionário horticultura 2003, Stata - Statistics/Data Analysis 7.0.

Os dados constantes da amostra utilizada neste trabalho referem-se às características de agricultores familiares. Os principais aspectos relacionados com o perfil da atividade desenvolvidos pelos horticultores foram resumidos na Tabela 3 e uma característica dessa atividade é que as pessoas que trabalham são todas remuneradas, sendo da família ou não. Cerca de $59 \%$ das pessoas recebem até 4 salários mínimos mensais. A assistência técnica pública é a mais utilizada, abrangendo $83 \%$ dos empreendimentos. Com relação à necessidade de financiamentos, a maioria trabalha com restrição de crédito e $43 \%$ já utilizaram crédito de custeio ou de financiamento oriundos de bancos.

Tabela 4 - Canal de comercialização

\begin{tabular}{lrr}
\hline Canal de comercialização utilizado & $\mathbf{N}^{\circ}$ horticultores & $\%$ \\
\hline Feiras & 176 & 60.5 \\
Ceasa & 136 & 46.7 \\
Venda na propriedade & 68 & 23.4 \\
Médios e pequenos mercados & 32 & 11.0 \\
Outros & 26 & 8.9 \\
Grandes supermercados & 21 & 7.2 \\
\hline Número de canais utilizados: & $\mathbf{N}^{\circ}$ horticultores & $\%$ \\
1 - utiliza um único canal & 138 & 47.6 \\
2 - utiliza dois canais & 136 & 46.9 \\
3 - utiliza até três canais & 16 & 5.5 \\
\hline \hline
\end{tabular}

Fonte: Questionário horticultura 2003, Stata - Statistics/Data Analysis 7.0. 
Conforme evidenciado na Tabela 4, 61\% dos horticultores do Distrito Federal utilizam as feiras para comercializarem sua produção. O CEASA é preferido por $46 \%$ dos produtores. Os grandes supermercados, responsáveis por volume expressivo do mercado local de Brasília, só são acessíveis a uma pequena minoria desses agricultores, o que os tornam bastantes vulneráveis em termos de poder de mercado. Outro aspecto que chama atenção é o fato de que cerca de $52 \%$ dos produtores recorrem a mais de um canal para comercializarem suas produções.

Deve-se ressaltar que nos cinco núcleos rurais visitados pelos pesquisadores, os agricultores contam com uma infra-estrutura básica considerável. A energia elétrica está disponível para $97 \%$ dos entrevistados; telefone; escola e transporte públicos para mais de $85 \%$; segurança e saúde pública em torno de $70 \%$; água tratada disponível para cerca de $40 \%$ dos entrevistados. Para analisar a condição de infra-estrutura pública disponível para o segmento foi criado o índice de infra-estrutura pública disponibilizada: Infra_pub - composto pela média dos valores dessas sete variáveis binárias que representam a infra-estrutura disponível na comunidade. Quanto mais próximo de um mais assistido é o produtor.

Tabela 5 - Índice de infra-estrutura pública disponibilizada

\begin{tabular}{crrr}
\hline Indice_iap & $\mathbf{N}^{\circ}$ horticultores & Percent & \% Acum. \\
\hline 0.0 & 2 & 0.69 & 0.69 \\
0.1429 & 3 & 1.03 & 1.72 \\
0.2857 & 21 & 7.24 & 8.97 \\
0.4286 & 26 & 8.97 & 17.93 \\
0.5714 & 27 & 9.31 & 27.24 \\
0.7143 & 33 & 11.38 & 38.62 \\
0.8571 & 91 & 31.38 & 70.00 \\
1.00 & 87 & 30.00 & 100.00 \\
\hline Total & 290 & 100 & \\
\hline \hline
\end{tabular}

Fonte: Questionário horticultura 2003, Stata - Statistics/Data Analysis 7.0.

Observa-se, na Tabela 5, que mais de $70 \%$ dos horticultores contam com situação privilegiada em termos de estrutura básica disponível, realmente contando com a assistência de serviços essenciais não só para o funcionamento de seus empreendimentos, praticamente com todo o 
conforto disponibilizado para toda a comunidade urbana. Conforme destacou Orsi (2001), a agricultura no Distrito Federal trabalha em contexto muito diferenciado da realidade nacional; o rural se confunde com urbano ou estão muito próximos.

\section{Resultados da estimação}

No Brasil, o elevado custo do dinheiro e as próprias incertezas que caracterizam a atividade agrícola tornaram os agricultores cada vez mais relutantes em contrair empréstimos bancários. Por outro lado, os produtores que possuem uma visão mais ampla de desenvolvimento econômico no meio rural sabem que a utilização de recursos de terceiros é uma alternativa importante, pois o crescimento econômico de suas atividades depende da adoção de novas tecnologias. $\mathrm{O}$ acesso ao crédito é percebido, bancário ou não, como uma maneira de acelerar tal processo e há estimativas de crescente participação de fontes alternativas de financiamento como complemento à participação do capital próprio nos investimentos essenciais para a sustentação econômica desses empreendimentos.

A amostra dos horticultores do Distrito Federal revela que 78,7\% dos agricultores gostariam de ter mais recursos à sua disposição, ou seja, adotam uma atitude de adesão ao crédito (Tabela 6). $\mathrm{O}$ acesso ao crédito permite antecipar investimentos em educação, inovações tecnológicas e capital físico que, de outra forma, só poderiam concretizar-se após um esforço de poupança de vários períodos. Esse processo de aumento do nível de investimentos repercute-se em aumento da produção, criação de novos empregos e aumento da renda ou do bem-estar geral.

Tabela 6 - Finalidade, situação líquida e fonte de crédito do horticultor

\begin{tabular}{rrrrr}
\hline Dummy & fcusteioD & finvestD & cred_constrD & dbancosD \\
\hline 0 & 166 & 224 & 62 & 153 \\
1 & 125 & 67 & 229 & 138 \\
$\mathrm{~N}^{\circ}$ obs & 291 & 291 & 291 & 291 \\
\hline \% participação (1) & $43,0 \%$ & $23,0 \%$ & $78,7 \%$ & $47,4 \%$ \\
\hline \hline
\end{tabular}

Fonte: Questionário horticultura 2003, Stata - Statistics/Data Analysis 7.0.

Procurou-se então estimar a probabilidade do horticultor estar utilizando crédito com recurso do modelo binomial probit, relacionando-se os fato- 
res que podem determinar a decisão do horticultor demandar ou não crédito para produção e procurando-se compreender a natureza e a intensidade do efeito que cada variável introduz nessa decisão (Tabela 7). Os resultados apresentados são absolutamente coerentes com a teoria e as estatísticas z e Qui-quadrado aprovam o modelo aplicado e as variáveis principais.

É possível observar que o aumento de R\$ 1 na renda do horticultor, relativamente ao valor médio de rendimento da amostra, provoca um acréscimo na probabilidade de utilização de crédito de custeio e diminui a de crédito de investimento. Chama atenção o fato de que a presença de assistência técnica oficial reforça a possibilidade de crédito de custeio, enquanto a assistência privada eleva a chance do crédito de investimento. O canal de comercialização utilizado também se mostrou capaz de influenciar na escolha de usar financiamento ou não; os horticultores que vendem seus produtos através de supermercados, empresas ou vendem diretamente sua produção, são menos propensos a demandarem crédito.

A educação mostrou influência positiva na decisão de tomar crédito em qualquer das situações analisada. Um ano de acréscimo na escolaridade aumenta em 5,2\% a probabilidade de utilização de crédito de custeio ou de investimento e em cerca de $6,7 \%$ a demanda por crédito em geral.

Tabela 7 - Efeitos marginais probit crédito custeio, investimento e restrição geral

\begin{tabular}{|c|c|c|c|c|c|c|c|c|c|c|c|c|}
\hline \multirow[b]{2}{*}{ variáveis } & \multicolumn{4}{|c|}{$\begin{array}{l}\text { Marginal effects after probit } \\
\begin{aligned} y=\operatorname{Pr}(\text { fcusteio } D) \text { (predict) } \\
=.3680249\end{aligned}\end{array}$} & \multicolumn{4}{|c|}{$\begin{array}{l}\text { Marginal effects after probit } \\
\begin{array}{c}y=\operatorname{Pr}(\text { finvest } D) \text { (predict) } \\
=.1816075\end{array}\end{array}$} & \multicolumn{4}{|c|}{ 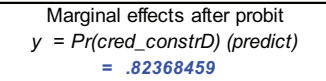 } \\
\hline & dy/dx & Std. Err & z & $P>|z|$ & $\mathrm{dy} / \mathrm{dx}$ & Std. Err & $z$ & $P>|z|$ & $\mathrm{dy} / \mathrm{dx}$ & Std. Err & $z$ & $P>|z|$ \\
\hline $\begin{array}{l}\text { Inw_renda } \\
\text { nand }\end{array}$ & 0.365 & 0.089 & 4.4 .110 & 0.000 & "-0.063 & 0.062 & -1.010 & 0.312 & 0.069 & 0.057 & 1.200 & 0.232 \\
\hline educ & 0.052 & 0.027 & 1.930 & 0.053 & 0.020 & 0.020 & 0.990 & 0.321 & 0.067 & 0.019 & 3.430 & 0.001 \\
\hline educ_sq & -0.002 & 0.001 & -1.610 & 0.107 & -0.001 & 0.001 & -1.010 & 0.313 & -0.003 & 0.001 & -3.400 & 0.001 \\
\hline nfam & 0.045 & 0.060 & 0.750 & 0.455 & 0.012 & 0.041 & 0.280 & 0.778 & -0.037 & 0.044 & -0.850 & 0.394 \\
\hline area & 0.004 & 0.001 & 2.900 & 0.004 & -0.001 & 0.001 & -1.670 & 0.096 & 0.000 & 0.001 & 0.500 & 0.620 \\
\hline area_cult & -0.010 & 0.006 & -1.610 & 0.108 & 0.002 & 0.004 & 0.460 & 0.643 & -0.004 & 0.004 & -1.150 & 0.249 \\
\hline assispub_D & 0.461 & 0.052 & 8.850 & 0.000 & 0.262 & 0.037 & 7.040 & 0.000 & 0.100 & 0.093 & 1.070 & 0.284 \\
\hline assispriv_D & 0.204 & 0.136 & 1.490 & 0.135 & 0.456 & 0.122 & 3.750 & 0.000 & 0.116 & 0.057 & 2.040 & 0.041 \\
\hline feirasD & 0.212 & 0.076 & 2.770 & 0.006 & -0.077 & 0.062 & -1.240 & 0.216 & 0.165 & 0.062 & 2.650 & 0.008 \\
\hline ceasaD & 0.134 & 0.076 & 1.770 & 0.077 & 0.012 & 0.056 & 0.210 & 0.832 & 0.148 & 0.052 & 2.830 & 0.005 \\
\hline mercadoD & -0.014 & 0.168 & -0.080 & 0.934 & -0.085 & 0.079 & -1.080 & 0.280 & 0.021 & 0.101 & 0.210 & 0.835 \\
\hline mpempD & -0.013 & 0.103 & -0.120 & 0.903 & -0.062 & 0.061 & -1.010 & 0.313 & 0.068 & 0.066 & 1.020 & 0.307 \\
\hline vdiretaD & -0.123 & 0.087 & -1.410 & 0.158 & -0.147 & 0.052 & -2.830 & 0.005 & -0.029 & 0.063 & -0.460 & 0.645 \\
\hline \multicolumn{13}{|l|}{$(*)$} \\
\hline Log likelihood & -138.233 & & & & -131.409 & & & & 128.869 & & & \\
\hline Number of obs & 289 & & & & 289 & & & & 289 & & & \\
\hline LR chi2(13) & 1117.75 & & & & 47.74 & & & & 42.76 & & & \\
\hline Prob $>$ chi 2 & 0 & & & & 0 & & & & 0 & & & \\
\hline Pseudo R2 & 0.2987 & & & & 0.1537 & & & & 0.1423 & & & \\
\hline
\end{tabular}


Conforme já enfatizado anteriormente, a necessidade de crédito não é diretamente observável, porém através do questionário aplicado pudemos identificar os horticultores demandantes de créditos e aqueles com auto-suficiência de recursos próprios para financiamento de suas atividades. Usando as respostas da variável dicotômica, o vetor de parâmetros $\gamma$ foi estimado através do probit, para geração da razão inversa de Mills, que será incorporada ao segundo estágio da estimativa. A Tabela 8 apresenta os resultados das regressões lineares das equações (1) e (2), com suas respectivas correções de pela razão inversa de Mills.

Estimou-se o modelo (4), em dois momentos distintos. As maiorias dos coeficientes estimados são estatisticamente diferentes de zero com $5 \%$ de significância e apresentam os esperados sinais teóricos. Foram 78,7\% por cento das observações apropriadamente classificadas como possuidores de restrição de crédito. As estimativas dos modelos probit, OLS e OLS ajustado parecem se ajustar bem aos dados da amostra. Nos parâmetros estimados nas Tabelas 7 e 8, o sinal de cada coeficiente expressa a direção da mudança de probabilidade para dada alteração na variável explicativa e o valor absoluto mensura a magnitude da influência dessa variável.

Na regressão do modelo (4) relacionado com os horticultores com crédito racionado da Tabela 7 , os estimados coeficientes da influência do crédito de custeio e de investimento são contrários, mas estatisticamente representativos, ao nível de $5 \%$ de significância. O número de integrantes da família e de trabalhadores também possui relevância para a formação da renda. A assistência técnica privada mostrou-se importante para ambas equações.

È também digno de nota que crédito de custeio, educação, área cultivada e canal de venda (Ceasa) possuem efeitos positivos sobre a renda desses agricultores. Conforme Vilela e Henz (2000), o mercado atacadista tem sido o principal canal de escoamento dos hortícolas. Estima-se que no Brasil entre $55 \%$ e $60 \%$ do volume de hortaliças sejam comercializados pela rede de Ceasa(s). Ressalte-se a crescente participação dos supermercados na distribuição desses produtos.

Por outro lado, a restrição de crédito em geral (cred_constrD), o tamanho da área e a assistência técnica pública são fatores que não ajudaram a melhorar a renda do horticultor; esta constatação sugere que crédito em geral, o tamanho da área e assistência técnica pública são fatores menos 
prováveis em contribuir para o incremento da renda do horticultor se a escolha do produtor for condicionada por uma restrição de crédito.

Tabela 8 - Comparativo regressão de primeiro e segundo estágios

\begin{tabular}{|c|c|c|c|c|}
\hline \multirow[b]{2}{*}{ variáveis } & \multirow{2}{*}{$\begin{array}{c}\text { OLS } \\
\text { Inw_renda } \\
\text { inicial } \\
\text { Coef. } \\
\end{array}$} & \multicolumn{3}{|c|}{$\begin{array}{c}\text { OLS } \\
\text { Inw_renda } \\
\text { two-step }\end{array}$} \\
\hline & & $P>|t|$ & Coef. & $P>|t|$ \\
\hline educ & 0.046 & 0.021 & 0.071 & 0.148 \\
\hline educ_sq & -0.002 & 0.025 & -0.003 & 0.151 \\
\hline nfam & 0.169 & 0.000 & 0.160 & 0.000 \\
\hline area & -0.004 & 0.000 & -0.004 & 0.000 \\
\hline area_cult & 0.015 & 0.000 & 0.015 & 0.000 \\
\hline assispub_D & -0.033 & 0.702 & 0.002 & 0.986 \\
\hline assispriv_D & 0.160 & 0.045 & 0.215 & 0.094 \\
\hline feirasD & -0.340 & 0.000 & -0.292 & 0.005 \\
\hline ceasaD & 0.152 & 0.006 & 0.206 & 0.067 \\
\hline mercadoD & -0.181 & 0.099 & -0.186 & 0.092 \\
\hline mpempD & -0.039 & 0.611 & -0.017 & 0.847 \\
\hline vdiretaD & 0.073 & 0.267 & 0.060 & 0.388 \\
\hline cred_constrD & -0.015 & 0.821 & -0.010 & 0.883 \\
\hline fcusteioD & 0.247 & 0.000 & 0.244 & 0.000 \\
\hline finvestD & -0.082 & 0.178 & -0.083 & 0.176 \\
\hline millratio & & & 0.234 & 0.582 \\
\hline _cons & 8.299 & 0.000 & 8.031 & 0.000 \\
\hline Number of obs & 289 & & & 289 \\
\hline$F(15,273)$ & 13.87 & & $F(16,272)$ & 12.99 \\
\hline Prob > F & 0 & & & 0 \\
\hline R-squared & 0.4326 & & & 0.4332 \\
\hline Adj R-squared & 0.4014 & & & 0.3999 \\
\hline
\end{tabular}

Fonte: Questionário horticultura 2003, Stata - Statistics/Data Analysis 7.0.

O resultado mostrado na Tabela 8 evidencia que o conjunto de variáveis de interesse apresenta resultados consistentes estatisticamente e o resultado da influência do crédito foi extremamente interessante. Ao se ampliar o nível de informação a respeito do crédito, requerendose sua destinação - custeio ou investimento - observamos resultados diferentes. $\mathrm{O}$ crédito de custeio mostrou-se mais benéfico para a renda 
do horticultor que o de investimento, o que é incoerente com o fato de as hortaliças serem culturas temporárias e, assim como outras culturas, necessitam de um investimento inicial para sua produção. "Mercados consumidores bastante densos e diversificados como Brasília” (Wilkinson, 1999) podem diminuir os níveis de investimentos necessários para viabilização da atividade, por outro lado, a inserção no mercado passa a ser elemento essencial. $\mathrm{O}$ crédito de custeio pode ser utilizado para melhorar as condições de comercialização da produção.

Os resultados encontrados neste estudo são parcialmente convergentes com os obtidos por Feder et al. (1990) em seu estudo sobre a influência do crédito para os produtores da província chinesa de Gongzhuling. As variáveis de controle apresentaram resultados esperados pela teoria econômica: a educação, área cultivada e número de trabalhadores apresentaram sinais positivos, por exemplo.

Na estimativa realizada, o coeficiente $(\delta=0.244)^{5}$ do crédito de custeio sugere que um incremento de um real na disponibilidade de recursos, para essa modalidade de crédito, pode ser projetada em elevar 0,27 centavos a renda do horticultor. Ou, ainda, que produtores que utilizam crédito obterão renda $27 \%$ maior que os que não utilizam. Em sentido contrário, age a utilização de crédito de investimento, onde o coeficiente de $(\delta=-0.082)$, corresponde a efeito negativo de $8,0 \%$ na renda do horticultor, tornando o efeito do crédito geral $(\delta=-0.015)$, embora de impacto menos expressivo, também negativo em cerca de 1,0\%.

Uma possível explicação para o efeito negativo da utilização do crédito de investimento pode estar associada com a questão fundiária do Distrito Federal. Tavares (1995) apud Orsi (2001), identificou 22 modalidades de ocupação de terras, que vão desde a existência de terras de propriedade do governo local e da União até terras particulares clandestinamente loteadas, por isso aparecem os arrendatários e as concessões de uso, dificultando o acesso a essa modalidade de crédito que é mais exigente em termos de comprovação de finalidade, e os agentes financei-

\footnotetext{
${ }^{5}$ A interpretação do coeficiente $\left(\delta_{\mathrm{i}}\right)$ da variável representativa do efeito do crédito, nessa regressão semilogaritmica, segue a interpretação sugerida por Halvorsen e Palmquist apud Gujarati(2000, p. 529). Pegue o antilog (na base e) do coeficiente dummy estimado e subtraia 1. Exemplo: o antilog de 0,1341 é 1,1435, subtraindo 1, significa que a variável é $14,35 \%$ maior.
} 
ros podem dificultar a liberação de recursos para os produtores que não possuem escritura definitiva. Já a obtenção de crédito de custeio pode ser facilitada com, por exemplo, a existência de um contrato e fornecimento de produção, ou histórico da produção em determinada localidade.

Gasques \& Spolador (2003) consideram o acesso restrito ao crédito um forte fator limitativo ao desenvolvimento da agricultura, no que se refere ao aumento da produção e às possibilidades de investimentos. Observouse que a maioria dos horticultores trabalhou com restrição de crédito, portanto o efeito negativo do crédito de investimento pode ter consequiência em escassez de recursos para investimentos, uma vez que expressiva parcela de horticultores poderia usar esses recursos na compra de máquinas e equipamentos necessários para adoção de novas tecnologias.

Na horticultura moderna, expressivas quantidades de custos são decorrentes da necessidade de compra de sementes, fertilizantes, energia, máquinas e equipamentos. No contexto de avanços tecnológicos constantes, os produtores que puderem investir tornam-se rapidamente absoletos e são excluídos do mercado, por isso, o acesso ao crédito em condições convenientes (ou a existência de mercado de crédito eficiente) é essencial para garantir que produtores com carência de recursos possam competir com os produtores de alta liquidez. Se potenciais e produtivos agricultores não obtiverem crédito em condições adequadas, esses produtores e a economia rural como um todo não atingem seu potencial de crescimento.

O estudo comprovou que o investimento em educação é positivamente remunerado pela atividade de horticultura no Distrito Federal. O coeficiente $(\gamma=0.071)$ indica melhoria de $7,1 \%$ na renda por ano adicional de estudo, mesmo considerando que os produtores possuem baixo nível de qualificação, pois $50 \%$ dos produtores contam com apenas o $1^{\circ}$ grau. Schultz (1964) argumenta que mudança das condições tecnológicas eleva o valor da escolaridade do agricultor, pois valoriza a capacidade empreendedora do produtor sendo fator de sucesso a sua habilidade em perceber, interpretar e responder aos novos eventos em contexto dinâmico.

Dessa forma, retornos de educação e de influência do crédito encontrados para a horticultura no Distrito Federal, são convergentes com o diagnóstico apontado pelo trabalho de Gentil (2004), que apontou a dificuldade de obtenção de crédito, a qualificação da mão-de-obra e a 
questão tecnológica como barreiras a serem superadas para o crescimento da horticultura no Distrito Federal.

Para a variável representativa da escolha do canal de distribuição $(\mu=$ - / ) o efeito é diversificado. Se por um lado o horticultor conta com um mercado consumidor denso e diversificado, com várias alternativas de canais de distribuição, existem fortes oscilações de retornos em termos da escolha do canal de venda. O Ceasa aparece como melhor alternativa positiva $(\mu=0.206)$ e é utilizado por $46,7 \%$ dos produtores. A utilização dos supermercados como canal de venda não mostrou relação favorável para os horticultores, talvez devido ao alto poder de mercado que esses mercados detém em Brasília, penalizando os produtores, o elo mais fraco da cadeia produtiva, devido ao seu curto ciclo de produção e alto custo de conservação de seus produtos, o que dificulta a estocagem como estratégia de negociação ou agregação de valor aos produtos.

A comercialização da produção através de feiras apresentou desempenho sofrível possivelmente pela consolidação dos supermercados como canal de venda, principalmente junto às populações de maior poder de consumo e renda, deslocando esse canal para regiões de menor poder aquisitivo e com produtos de menor valor agregado. Esse resultado é de certo modo inesperado por sua importância e tradição como mecanismo de acesso desse segmento ao mercado consumidor. As feiras-livres são um dos mais antigos instrumentos de varejo com presença generalizada em todo o país e continuam a desempenhar importante papel na comercialização de hortaliças nos grandes centros urbanos (Maluf, 1999).

O resultado apresentado na negociação da produção com os mercados reforça a constatação de Melo (2001) de que as grandes redes de supermercados tendem a se apropriarem de grande parte das parcelas dos preços pagos pelos consumidores, comprimindo os preços pagos e, por conseqüência, a renda do produtor. De 1996 a 2001, os supermercados aumentaram de $24 \%$ para $35 \%$ a comercialização direta de hortaliças (Melo, 2001), esses resultados sugerem, portanto que a questão da comercialização deve ser cuidadosamente analisada em qualquer política de fortalecimento da renda do horticultor do Distrito Federal. Isso reforça o diagnóstico do próprio governo do Distrito Federal de que o principal desafio enfrentado por esse agronegócio, que apresenta ta- 
xas de crescimentos de cerca de $4,5 \%$ ao ano, é colocar-se no mercado de forma lucrativa.

Uma queixa generalizada é a falta de poder de mercado do pequeno agricultor, quando comparado com os agentes econômicos dos quais compra insumos e os que compram sua produção. Tais produtores, em geral, contam com poucas alternativas para venda de seus produtos e não muitas para compra de insumos, porém a caracterização desse mercado como monopsônio ou monopólio não parece muito consistente. Afinal, pode-se observar na horticultura no Distrito Federal, por exemplo, a presença de vários canais alternativos ou instrumentos de comercialização.

Os resultados permitem associar, de forma mais coerente, o relativamente fraco poder de mercado dos horticultores à sua inadequada capacidade de compreensão do funcionamento do mercado, reflexo de baixo nível de escolaridade, falta de visão de longo prazo e baixa capacidade e organização.

Uma questão que deve ser investigada em trabalhos futuros é a do funcionamento do mercado de crédito do Distrito Federal. Esse trabalho presumiu mercado de crédito eficiente para os horticultores, desconsiderando qualquer problema alocativo de crédito para essa atividade seja decorrente de assimetria de informações ou de competição imperfeita.

\section{Conclusão}

Os resultados encontrados neste estudo são convergentes com os obtidos por Feder et al. (1990) em seu estudo sobre a influência do crédito para os produtores da província chinesa de Gongzhuling. Baseado nas estimativas realizadas, o coeficiente $(0.244)$ do crédito de custeio mostra que um incremento de $\mathrm{R} \$ 1,00$ na disponibilidade de recursos para essa modalidade de crédito pode ser projetada em elevar $\mathrm{R} \$ 0,27$, ou aproximadamente $27 \%$ a renda do horticultor.

Os resultados mostram que a hipótese (1) de que a ampliação da capacidade de o acesso ao crédito propiciado pela política de fortalecimento afetou positivamente a renda do agricultor familiar não foi totalmente confirmada. $\mathrm{O}$ agricultor familiar utilizou basicamente crédito para investimento ou custeio da produção, sendo inexpressiva a parcela de recursos disponíveis para comercialização. Esse resultado é coerente 
com os encontrados por Feijó (2003) e FECAMP (2003), que analisaram especificamente o impacto do PRONAF na agricultura familiar em diversos estados brasileiros, que concluíram por ausência de efeito produtivo e associação negativa entre o PRONAF e a renda do agricultor, respectivamente. Também é compatível com os resultados encontrados por Sial \& Carter (1996) que concluíram que os programas de crédito voltados para o setor não funcionaram adequadamente no Punjab, Paquistão.

A pesquisa permitiu inferir (2) que a escolaridade afeta positivamente a renda dos agricultores familiares. Na horticultura do Distrito Federal cada ano adicional de estudo recebe um prêmio de 7,1\% de aumento na renda média, índice ligeiramente maior que a média regional para a agricultura familiar para o período de 1992 a 2002.

A hipótese (3) de que o valor da produção é afetado pela escolha do canal de comercialização foi confirmada e os resultados apontam que as negociações através de Ceasa e venda direta agregam maior valor à renda do horticultor. Ficou evidenciada a desvantagem da negociação através dos grandes supermercados, que tendem a comprimir, conforme constatado por Melo (2001), a remuneração dos fornecedores de hortaliças. A feira não se mostrou boa alternativa de comercialização, pois se trata de canal tradicional de comercialização, mas tendendo a localizar-se na periferia com produtos de menor valor agregado. Podese dizer que esses resultados são particularmente mais interessantes ao evidenciar a importância da existência de crédito para a comercialização, como uma alternativa para melhorar a renda do agricultor familiar que, de certo modo produz, mas usualmente possui baixo poder de articulação com o mercado.

Os resultados da horticultura do Distrito Federal reforçam a complexidade do universo da agricultura familiar. Os produtores contam com algumas características específicas melhores que a média nacional - educação e renda - e estão localizados próximos de mercado consumidor e podem dispor de assistência técnica pública e privada. Ainda assim seus resultados não são muito diferentes dos demais agricultores familiares de outras regiões. Em Brasília, no entanto, a questão crítica para esses produtores é a comercialização, o que demonstra a necessidade de enfatizar-se cada vez mais esse aspecto na política específica de fortalecimento do segmento. 


\section{Referências bibliográficas}

ABRAMOVAY, Ricardo, Bittencourt, Gilson A.. Inovações Instituições no Financiamento à Agricultura Familiar: o Sistema Cresol. IPEA - Texto para Discussão 502, Brasília, 1997.

ABRAMOVAY, Ricardo. Paradigmas do Capitalismo Agrário em Questão. São Paulo: Hucitec, 1992. (Estudos Rurais, 12).

CARTER, Michael R. Equilibrium credit rationing of small farm agriculture. Journal of Development Economics, v. 28, n. 1, p. 83-103, 1988.

CARTER, Michael R. The impact of credit on peasant and credit constraints in Nicaragua. Journal of Development Economics, v. 31, p. 13-36, 1989.

CARTER, Michael R.; WIEBE, Keith D. Access to capital and its impact on agrarian structure and productivity in Kenya, American Journal of Agricultural Economics, Vol. 72, p. 1141-1150, 1990.

CONCEIÇÃO, Júnia C.P.R. da; GASQUES, José G.; CARVALHO, Alexandre, CONCEIÇÃO, Pedro H. Z. da. Relação entre o pib agrícola e crédito rural no Brasil: aplicação do teste de causalidade de Granger. In: CONGRESSO BRASILEIRO DE ECONOMIA E SOCIOLOGIA RURAL, XXXVI. Poços de Caldas, M.G., Anais, v.2 p.127-138, 1998.

FECAMP. Estudos de caso em campo para avaliação dos impactos do PRONAF. Convênio PCT/IICA-PRONAF e Fundação de Economia de Campinas - FECAMP. Campinas, outubro 2002. www.pronaf.gov.br/ textos_e_estudos/fecamp.htm, acesso em 26.11.2003.

FEDER, Gerson et al. The relationship between credit and productivity in Chinese agriculture: a microeconomic modelo of disequilibrium. American Journal of Agricultural Economics, v. 72, p. 1151-1157, Dec.1990.

FEIJO, Ricardo L.C. T. Avaliação preliminar do impacto do PRONAF na produtividade da agricultura familiar. Fórum Banco do Nordeste de Desenvolvimento - VIII Encontro Regional de Economia Nordeste: Desafios da Transformação. Fortaleza (CE), 17 e 18 de julho de 2003.

GASQUES, José G., Spolador, Humberto F. S. Taxa de juros e políti- 
cas de apoio interno à agricultura. IPEA - Texto para Discussão 952, Brasília, 2003.

GASQUES, José G.; BASTOS, Eliana T. Crescimento da Agricultura. IPEA - Nota Técnica - Boletim de Conjuntura 60, Brasília, março 2003.

GASQUES, José G.; CONCEIÇÃO, Júnia C. P. R. da. Transformações estruturais da agricultura e produtividade total de fatores. IPEA - Texto para Discussão 768, Brasília, 2000.

GUANZIROLI, C. Reforma e Perfil da Agricultura Familiar no Brasil. Projeto INCRA/FAO. Brasília, 1997.

GURAJATI, Damodar N. Econométrica básica. Makron Books, São Paulo, 2000.

HECKMAN, James Varieties of selection bias. American Economic Review, Paper and Proceedings v. 80, n. 2, p. 313-318, 1990.

HECKMAN, James. Shadow Prices, Market Wages, and Labor Supply, Econometrica, 1, 679-694. 1974.

KHANDKER, Shahidur R., Faruqee, Rashidur R.. The impact of farm credit in Pakistan. Working Papers - Agriculture, Land, Commodity, Prices, Markets n. 2653 World Bank, 2001.

LOUREIRO, Paulo R. A. Francisco G. Carneiro and Sachsida, A.Race and Gender Differentials: An Analysis for the Urban and Rural Sector in Brazil. Journal of Economic Studies Volume 31 Nº 2 May, (2004).

MELO, Mário Felipe. Crise e Reestruturação do Setor Olerícola do Distrito Federal na década de 1990. Orientador: Adelaide dos Santos Figueiredo. Brasília: Universidade Católica; 89p. Dissertação. (Mestrado em Economia de Empresas). Dezembro 2001.

MINISTÉRIO DO DESENVOLVIMENTO AGRÁRIO. Balanço da Reforma Agrária e da Agricultura Familiar 2001.www.incra.gov.br/_htm/serveinf/balanço, acesso em 23.09.2003.

ORSI, Sérgio Dias. Desafios institucionais para inserção das pequenas agroindústrias rurais no Distrito Federal. Orientador: John Wilkinson. Seropédica: Universidade Federal Rural do Rio de Janeiro; 202f. Dis- 
sertação. (Mestrado em Ciências do Desenvolvimento e Agricultura). Outubro 2001.

SCHULTZ, Theodore W. Transforming traditional agriculture. New Haven and London: Yale University Press, 1964.

SECRETARIA DE AGRICULTURA, PECUÁRIA E ABASTECIMENTO SEAPA. Horticultura. www.as.df.gov.br/prorural_projeto_horticultura. html, acesso em 20.01.2004.

SIAL, Maqbool H.. Carter, Michael R.. Financial market efficiency in an agrarian economy: microenometric analysis of the Pakistani Punjab. Journal of Development Studies, v. 32, n. 5, jun., p. 771-798, 1996.

SILVA, Nancy de Deus Vieira e Kassouf, Ana L. Mercados de Trabalho Formal e Informal: uma análise da discriminação e da segmentação. Nova Economia Aplicada Vol.10 No 1 Jul pp.41-77. Revista do Departamento de Ciências Econômicas da UFMG. 200.

SPOLADOR, Humberto F.S. Reflexões sobre a experiência brasileira de financiamento agrícola. Orientador: Fernando Bento Homem de Melo. Piracicaba: Universidade de São Paulo, 93p. Dissertação. (Mestrado em Economia Aplicada). Dezembro, 2001.

VILELA, Nirlene J. e HenZ, Gilmar P. Situação Atual da Participação das Hortaliças no Agronegócio Brasileiro e Perspectivas Futuras. Cadernos de Ciência \& Tecnologia, v. 17, n. 1 p. 71-79, jan./abr., Brasília, 2000. WILKINSON, John. Cadeias Produtivas para a Agricultura Familiar. Revista de Administração da UFLA. V. 1, n. 1 jan./jun. p. 34-41, Rio de Janeiro, 1999.

Recebido em abril de 2005 e revisto em maio de 2006. 